\title{
Los límites del perdón en el pensamiento de Hannah Arendt: un posible aporte desde la perspectiva derridiana
}

\author{
[The limits of forgiveness in Hannah Arendt's thought: \\ a possible contribution from Derrida's perspective]
}

\author{
María E. Wagon*
}

\begin{abstract}
Resumen
Arendt concibe el perdón como una forma de acción que posee la facultad de revertir las consecuencias desplegadas por el actuar mismo pero que encuentra limitada su capacidad de intervención en lo que respecta al mal totalitario. En el marco de la concepción arendtiana de la acción el mal mencionado es imperdonable en tanto el perdón se encuadra en el marco de la acción y el mal totalitario, precisamente, anula la capacidad humana de actuar. Derrida, en cambio, sostiene que el perdón incondicional, en virtud de su pureza, debe aplicarse a aquello considerado imperdonable. En esta investigación se analizará la relación entre las nociones arendtianas de natalidad y perdón para luego ponerlas en cuestión con la concepción derridiana del perdón puro. El objetivo de este trabajo es, por un lado, hacer hincapié en los límites propios de la concepción arendtiana del perdón y, por otro, intentar superar dichos límites desde el aporte de la perspectiva derridiana. Finalmente se concluirá que el hecho de la natalidad entendido como característica de la acción concebida en tanto inicio actualiza en forma máxima su condición milagrosa en la acción de perdonar lo imperdonable, esto es, el mal totalitario.
\end{abstract}

Palabras-clave: Arendt; Derrida; Natalidad; Mal; Perdón; Perdón puro.

\begin{abstract}
Arendt conceives forgiveness as a form of action that has the power to reverse the consequences deployed by the act itself although it is limited in its ability to act with respect to totalitarian evil. Under the framework of the arendtian's theory of action the mentioned evil is unforgivable in both forgiveness falls under the framework of the action and totalitarian evil, precisely, overrides the human capacity to act. Derrida, however, contends that unconditional
\end{abstract}

* Licenciada en Filosofía por la Universidad Nacional del Sur (UNS), Buenos Aires, Argentina. Doctoranda en Filosofía por la Universidad Nacional del Sur (UNS). Miembro del Instituto de Investigaciones Económicas y Sociales del Sur (IIESS [UNS/CONICET]. Becaria doctoral del Consejo Nacional de Investigaciones Científicas y Técnicas (CONICET). Correo Postal: 12 de Octubre 1198. $8^{\circ}$ Piso B-8000 CTX Bahía Blanca, Argentina. E-mail: mariawagon@gmail.com. 


\section{Ágora Filosófica}

forgiveness, by virtue of its purity, must be applied to what is considered unforgivable. In this research will analyze the relationship between Arendt's notions of natality and forgiveness to then put them in question with Derrida's conception of pure forgiveness. The aim of this paper is, firstly, to emphasize the proper limits of Arendt's conception of forgiveness and, secondly, try to overcome these limits from the contribution of Derrida's perspective. Finally it is concluded that the fact of natality understood as the condition of the action in both start updated, maximally, their miraculous condition in forgiving the unforgivable action, totalitarian evil.

Key-words: Arendt; Derrida; Natality; Evil; Forgiveness; Pure forgiveness

\section{Introducción}

En los últimos tiempos el concepto de perdón, no obstante su origen cristiano, ha cobrado gran relevancia en el ámbito de interés de la filosofía política. Los pedidos públicos de perdón por parte de instituciones y representantes estatales que han tenido lugar en el escenario mundial dirigen el interés de los teóricos políticos hacia la acción de perdonar y sus implicancias en el ámbito jurídico-político y del derecho. Hannah Arendt, en su carácter de pensadora política, se aboca al análisis de la noción de perdón entendida como una forma de la acción y como una categoría clave a la hora de reflexionar sobre el problema del mal, sus consecuencias y sus agentes.

En la teoría política arendtiana la noción de natalidad cumple un rol fundamental en tanto es concebida como la capacidad inherente a la acción humana de introducir la novedad en el transcurso del mundo. El individuo, por medio de la acción, no solo tiene la posibilidad de comenzar una serie nueva de acontecimientos sino que él mismo es un comienzo. A su vez, la acción presenta, también, características negativas, una de ellas es la irreversibilidad entendida como la imposibilidad de deshacer aquello llevado a cabo en el pasado. Arendt (2009) encuentra en la categoría de perdón la posibilidad, dentro del marco de la acción misma, de redimir al ser humano de las consecuencias de la irreversibilidad mencionada.

La pensadora considera que por medio del perdón es posible liberar al individuo de su acto pasado y de las consecuencias del mismo. Ahora bien, la autora sostiene que el perdón no es omniabarcante puesto que según su criterio hay hechos que, por la magnitud de su horror, trascienden las 
posibilidades de la acción humana, a saber: el mal totalitário ${ }^{1}$, un mal imperdonable. Respecto a la relación entre dicho mal y el perdón, Derrida (2003) sostiene, en contraposición con la propuesta arendtiana, que el perdón en sentido puro, lejos de no aplicar y en virtud de su pureza, debe estar siempre vinculado a lo imposible, es decir, a lo imperdonable, puesto que es desde ese lugar desde donde se actualiza su capacidad revolucionaria y su facultad de cambiar el curso de la historia. Esta capacidad de introducir la novedad y de insertarse en la realidad existente, revolucionándola, vincularía estrechamente las nociones de perdón y natalidad, ambas categorías inherentes a la concepción arendtiana de la acción.

En esta investigación se realizará, en primer lugar, una caracterización breve de las nociones arendtianas de acción, natalidad y perdón, en segundo lugar se expondrá el análisis del perdón puro que propone Derrida (2003), y en un tercer momento se pondrá en cuestión la sentencia arendtiana que sostiene la imposibilidad de perdonar el mal totalitario. El mencionado análisis crítico se llevará adelante de la mano de la propuesta derridiana y de un análisis en profundidad de las concepciones arendtianas de las categorías de natalidad y perdón. Finalmente se argumentará que es en la acción de perdonar el mal absoluto donde la natalidad entendida como la capacidad de hacer lo inesperado y hasta lo improbable, es elevada a la cúspide de sus potencialidades y reafirmada en su condición de milagro.

\section{Acción, natalidad y perdón en la teoría política arendtiana}

\subsection{La acción}

Arendt (2009) se aboca al análisis de la noción de vita

\footnotetext{
${ }^{1}$ Como el objetivo de este trabajo es problematizar el concepto de perdón en la propuesta arendtiana, en esta investigación se utilizará la expresión mal totalitario o mal absoluto de manera indistinta y no se ahondará en lo problemático que resulta el abordaje del problema del mal en la teoría arendtiana. Para un mayor análisis de la controversia respecto a las nociones de mal radical y banalidad del mal cf. Arendt (1998, 2003a, 2007), Bernstein (2000), Bilsky (2001), Pendas (2007), Hayden (2010), Neiman (2010), Babich (2014) entre muchos otros.
} 
activa, concepto que alude a tres actividades propias del género humano: labor, trabajo y acción. La labor es definida como la actividad propia del proceso biológico del cuerpo humano por medio de la cual se logra la supervivencia.

La condición humana de la labor es la vida. Por trabajo la autora entiende aquella actividad que le proporciona al individuo un mundo artificial de cosas. En tal sentido, el trabajo no está inmerso en el ciclo natural de la vida del hombre, sino que lo trasciende en la durabilidad del producto de dicha actividad.

Arendt no reduce el mundo creado por el trabajo a su utilidad sino que lo concibe como "la verdadera morada humana (...), interpuesta no solo entre ser humano y naturaleza, sino (...) entre uno y otro ser humano, (...) de manera que al mismo tiempo separa y une" (JONAS, 2000, p. 31).

La condición humana del trabajo es la mundanidad. Por último, la acción es entendida como la actividad que acontece "entre" los hombres y que no requiere de la mediación de cosas o de materia alguna. Su condición humana es la pluralidad, condición indispensable de toda vida política. "Estas tres actividades y sus correspondientes condiciones están íntimamente relacionadas con la condición más general de la existencia humana: nacimiento y muerte, natalidad y mortalidad" (ARENDT, 2009, p. 22).

En la propuesta política arendtiana la acción es la única actividad exclusivamente humana que requiere necesariamente la presencia de otros para ser llevada a cabo, con lo cual Arendt establece una estrecha relación entre el actuar y el estar juntos. Los hombres se diferencian entre sí mediante el discurso y la acción, atributos que se fundamentan en la condición de la pluralidad que alberga en su interior la igualdad y la distinción ${ }^{2}$.

Para Arendt, es el discurso compartido el que le otorga realidad a los hechos, es mediante la materialización de la acción y el discurso que los seres humanos se diferencian unos de otros y se igualan en su pluralidad. Mediante la palabra y la acción el ser humano se inserta en el mundo y, por medio de la acción, además, inicia una cadena nueva de acontecimientos.

\footnotetext{
${ }^{2}$ Arendt (1997) distingue entre dos tipos de pluralidad, dos modos diferentes del estar juntos: entre seres humanos iguales entre sí, de donde surge la acción; y entre uno y su sí mismo, relación de la que surge el pensar.

62 - Universidade Católica dePernambuco
} 
Es en la acción humana donde Arendt ancla la idea de que los hombres no han nacido para morir sino para iniciar algo nuevo en el mundo ${ }^{3}$.

La acción de la que es capaz el hombre trae ínsita la noción de natalidad, el discurso, por su parte, a través de la pluralidad humana expresa la distinción y singularidad de cada individuo. A su vez, la acción requiere del discurso para completarse puesto que es por medio de la palabra que se visualiza el sujeto actuante. La acción y el discurso acaecen "entre" los hombres, en la trama de las relaciones humanas, de modo que no pueden darse en aislamiento, es decir, se desvanecen en situación de soledad, son frágiles en relación con los procesos y productos de la labor y el trabajo y requieren de la recepción de otros que los vean, los oigan y los recuerden (BIRULÉS, 2002) ${ }^{4}$. A diferencia de la materialidad de los procesos y productos de la labor y del trabajo, la acción y el discurso no dejan tras de sí ningún rastro concreto sino que requieren de los otros, de su memoria y sus narraciones, para poder perdurar en el tiempo.

En otras palabras, la esfera pública en tanto espacio de aparición en el que se manifiestan el discurso y la acción es una esfera de igualdad entre seres desiguales. Los procesos que se inician por medio de la acción humana son impredecibles y, en este sentido, incontrolables. El hombre carece de la capacidad de deshacer aquello que realizó en el mundo y de anticipar las consecuencias de su obrar. Tal incapacidad surge del hecho de que, como se expusiera con anterioridad, en la acción misma confluyen una pluralidad de actores, de modo que resulta imposible que el individuo en su singularidad pueda tener el control total de las consecuencias de su obrar. El perdón y la promesa son las dos alternativas que Arendt encuentra dentro del marco de la acción misma para hacer frente a dichas incapacidades.

3 Arendt realiza, aquí, una referencia implícita a la propuesta filosófica de Heidegger. Para una mayor profundización sobre las posibles relaciones entre los pensamientos de ambos autores cf. Canovan (1992), Kristeva (2001), Bárcena (2002), Birulés (2002), Ramírez García (2009), Bagedelli (2011), entre otros.

${ }^{4}$ Birulés (2002) remarca que no se debe confundir la noción de pluralidad con la de alteridad. La pluralidad hace referencia a la singularidad y particularidad que surge a través del discurso y de la acción, y se da entre seres humanos. La relación de alteridad, en cambio, acontece entre el individuo y las cosas. 


\subsection{El concepto de natalidad}

Lo primero que resulta importante remarcar en este punto es que la crítica temprana de la obra de Arendt no profundizó en el análisis del concepto de natalidad, y lo relegó a un papel secundario en la teoría política de la autora. Sin embargo, a finales del siglo pasado dicho concepto comenzó a ser objeto de análisis de los estudios críticos, los cuales le otorgaron una relevancia de la que había carecido hasta ese momento. Se comenzó a observar que la noción de natalidad aparecía en casi todas las obras de Arendt, y que su rol no era secundario o complementario sino que cumplía una función central en los pasajes y argumentos en los cuales era utilizada. "[E]1 término (...) es siempre la bisagra entre una concepción fatalista del desarrollo de los asuntos humanos y la afirmación de las posibilidades de los hombres para (...) torcer los destinos del mundo" (Bagedelli, 2011: 37).

Al realizar un rastreo de la aparición de la noción de natalidad en la obra de Arendt, se puede afirmar que el primer acercamiento a dicho concepto como categoría política clave en su pensamiento fue en un artículo publicado en Partisan Review en 1953. En él, Arendt cita a Agustín en relación a la creación del hombre como un "inicio" en sí mismo, quien es dotado, además, con la capacidad de iniciar una cadena nueva de acontecimientos en el mundo. Sin embargo, es recién en 1958 (Arendt, 2009) donde la autora utiliza explícitamente el término natalidad y lo desarrolla en profundidad, vinculándolo estrechamente con la noción de acción ${ }^{5}$. Como expone Bagedelli (2011), es a partir de esta obra que Arendt introduce el concepto en reediciones de escritos anteriores, a saber: Arendt (1998, 2001).

En relación a lo expuesto, Tsao (2010) remarca que existe una diferencia significativa entre la interpretación arendtiana de la obra de Agustín que se encuentra en la primera edición de Los orígenes del totalitarismo (publicado en 1951 pero finalizado dos años antes, en 1949) y la que se observa en La condición humana (1958). Tal transformación anunciaría una reorientación del

\footnotetext{
${ }^{5}$ Cabe mencionar la observación de Vatter (2006), quien plantea que ya en los fragmentos escritos por Arendt en 1950, publicados bajo el nombre: ¿Qué es política?, se puede observar una primera alusión a dicha problemática, específicamente en el análisis que realiza la autora de la noción de pluralidad.

64 - Universidade Católica de Pernambuco
} 
pensamiento de la autora por medio de la cual el concepto de natalidad cobra la relevancia política que Arendt le concede a partir de la última etapa de su producción teórica ${ }^{6}$.

En lo que respecta específicamente a la caracterización de la categoría de natalidad, debe tenerse presente que si bien las nociones de labor, trabajo y acción se ven vinculadas a dicho concepto en tanto tienen la misión de preservar a los nuevos llegados al mundo, es la acción la que permanece estrechamente vinculada a él. Es en la capacidad de actuar del recién llegado donde se ve reflejado el nuevo comienzo inherente a todo nacimiento. "Con cada nuevo nacimiento nace un nuevo comienzo, surge a la existencia potencialmente un nuevo mundo" (Arendt, 1998: 373). En consecuencia, si se tiene presente que la actividad política por excelencia es la acción, no puede ser la mortalidad, sino la natalidad la categoría política más relevante ${ }^{7}$.

Como se expusiera anteriormente, es inherente al concepto arendtiano de política la noción de pluralidad, "[1] a pluralidad es la ley de la tierra" (Arendt, 1997: 31). Dicha noción es fundamental para la acción y el discurso, puesto que ambos pueden darse únicamente en un ambiente plagado de otros que den testimonio de su realidad. En el análisis arendtiano, el hombre, por el hecho de nacer, no solo tiene la posibilidad de comenzar una serie nueva de acontecimientos sino que él mismo es un comienzo. "Programado o no, cada nacimiento es un hiato en la cadena, un inicio, un comienzo, un momento de pura libertad" (Bárcena, 2002: 111).

Arendt (2009) afirma que lo nuevo que llega al mundo con el nacimiento de cada hombre lo hace en forma de milagro, pues el individuo, al ser capaz de acción, tiene la posibilidad de hacer lo inesperado, hasta lo improbable. La experiencia de dicha capacidad humana es la que da fe y esperanza a los asuntos humanos. "El

\footnotetext{
${ }^{6}$ Tsao (2010) afirma que la mencionada diferencia interpretativa ha sido difícil de percibir debido a las reediciones de Los orígenes del totalitarismo en las cuales se agregó un capítulo basado en el ensayo de Arendt publicado en 1953. En la primera edición de dicha obra, del año 1951, no se hace alusión ni a la natalidad ni se lo cita a Agustín respecto a la creación del hombre como inicio. En la segunda edición del año 1958, en cambio, Arendt agrega la cita agustiniana: "[Initium] ut esset homo creatus est" (Arendt, 1998: 383), y hace una referencia a la misma en el capítulo agregado: "Ideología y terror de una nueva forma de gobierno" (Arendt, 1998).

${ }^{7}$ Ver nota ${ }^{\circ} 3$.
} 
milagro que salva al mundo (...) de su ruina normal y 'natural' es (...) el hecho de la natalidad, en el que se enraíza ontológicamente la facultad de la acción" (Arendt, 2009: 266). La autora hace hincapié en la particularidad e irrepetibilidad de cada nacimiento, en el hecho de la natalidad, a la que sin vacilar designa como "el milagro de la vida" (Kristeva, 2001).

En este sentido, la natalidad es concebida no solo como un proceso natural, sino como un acontecimiento que en su acaecer establece una ruptura con dicho proceso ${ }^{8}$. Por lo dicho, Bárcena (2002) entiende que la natalidad se convierte en la categoría política clave del pensamiento arendtiano, en tanto se la entiende no solo como reproducción de la vida sino como la interrupción del proceso vital.

[L]os hombres, aunque han de morir, no han nacido para eso, sino para comenzar algo nuevo. (...) Con la creación del hombre, el principio del comienzo entró en el mundo; lo cual, naturalmente, no es más que otra forma de decir que, con la creación del hombre, el principio de la libertad apareció en la tierra ${ }^{9}$ (Arendt, 1995: 107).

El recién nacido es un otro que por primera y única vez adviene al mundo $y$ al hacerlo introduce una nota de heterogeneidad en la pluralidad de seres humanos de la que es parte. A través de dicha pluralidad se abre la posibilidad de la revelación de los seres humanos en su indiscutible singularidad mediante sus acciones y palabras (López, 2011).

\footnotetext{
${ }^{8}$ Canovan (2000), si bien coincide con los demás críticos en que Arendt entiende la natalidad como la posibilidad de un nuevo origen, resalta el hecho de que los individuos, al nacer, lo hacen en estado de barbarie, en el sentido de que con cada nacimiento la barbarie invade a la civilización. Es aquí donde cobran protagonismo las leyes, encargadas de proteger y de mantener la estabilidad del mundo humano.

${ }^{9}$ Extracto de una conferencia probablemente pronunciada en 1957. El original, titulado «Labor, Work, Action. A lecture» se halla depositado en «The Papers of Hannah Arendt» de la Library of Congress. En esta investigación se trabajó con la edición al español de De la historia a la acción, texto en el que se incluye dicha conferencia, traducción de Fina Birulés.

66 - Universidade Católica dePernambuco
} 


\subsection{El perdón}

Antes de comenzar a exponer la caracterización arendtiana del perdón, es preciso remarcar que la exposición y el análisis de dicho concepto acarrean un número de dificultades que deben tenerse presentes, principalmente si se considera que la autora no le dedica al mencionado concepto ningún tratado ni ensayo especial, sino que su abordaje debe ser rastreado a lo largo de toda su obra.

Madrid Gómez Tagle (2008) se refiere a la problemática del perdón en la teoría arendtiana como sujeta a dos dificultades, a saber: la dificultad arqueológica y la genealógica. La primera se relaciona con la necesidad de reconstrucción conceptual que se requiere para poder aprehenderla y la segunda con la tradición que enmarca, por un lado, el concepto mismo de perdón y, por otro, el marco de análisis arendtiano. A los efectos del objetivo de esta investigación se le dedicará mayor atención a la dificultad arqueológica.

Como se mencionó anteriormente, Arendt (2009) caracteriza la acción como impredecible e irreversible, sin embargo considera que existe la posibilidad, en el marco del actuar mismo, de redimir al ser humano de la impredecibilidad e irreversibilidad mencionadas, posibilidad que tiene su fundamento en las facultades de prometer y de perdonar respectivamente. La capacidad de perdonar es la única posibilidad de que dispone el hombre para revertir los actos del pasado ${ }^{10}$ en tanto "[e]1 perdón restaura y rehabilita (...) la capacidad humana de actuar" (Madrid Gómez Tagle, 2008: 140). Sin la mencionada capacidad de perdonar el ser humano quedaría sujeto por siempre a un primer y único acto del que no podría escaparse. "Sin ser perdonados, liberados de las consecuencias de lo que hemos hecho, nuestra capacidad para actuar quedaría (...) confinada a un solo acto del que nunca podríamos recobrarnos" (Arendt, 2009: 257). Hilb (2013a) menciona que en los primeros tratamientos arendtianos sobre el perdón, este era abordado en su perfil antipolítico, es decir, en su

${ }^{10}$ Canovan (1998) aclara que la capacidad inherente a la facultad del perdón de romper la cadena causal de las consecuencias desencadenada por la acción aplica únicamente al ámbito humano. Es decir, por medio del perdón no es posible revertir las consecuencias que la acción humana desencadenó, por ejemplo, en la naturaleza. 
aspecto de evento personal y religioso, y es recién en La condición humana en donde Arendt se refiere al perdón como capacidad eminentemente política y plural. La facultad humana del perdón se sostiene y sustenta en la noción de pluralidad puesto que el hombre no puede perdonarse a sí mismo, sino que requiere de otros para ser perdonado y para perdonar.

Arendt (2009) considera que es en la figura de Jesús de Nazaret $^{11}$ donde debe ubicarse el surgimiento de la noción de perdón en tanto facultad humana, puesto que en sus orígenes era considerado una prerrogativa divina. A pesar del perfil antipolítico del cristianismo, Arendt toma la experiencia cristiana del perdón como vía para pensar la acción entendida como el único medio posible que puede liberar a los individuos del peso del pasado (Birulés, 1997). El perdón en sentido cristiano se fundamenta en la noción de amor, el individuo perdona al transgresor por amor a él, en cambio Arendt sostiene que el amor no es necesario ni mucho menos imprescindible para el perdón, sino que todo lo que se requiere es el respeto mutuo (Canovan, 1992). El amor no puede ser el fundamento del perdón en la teoría arendtiana puesto que la autora lo considera como el destructor del "en medio de que nos relaciona y nos separa de los demás” (Arendt, 2009: 261). Es decir que, a criterio de la autora, el amor no solo es a-político sino también anti-político. El respeto, en cambio, es concebido por Arendt como una suerte de amistad sin cercanía ni intimidad (amistad entendida en el sentido de la "philía politikê" aristotélica). Es decir, una consideración de la persona desde la distancia que establece el mundo existente entre dos seres humanos.

En cuanto a la transgresión, Arendt (2003b) especifica que existen diferentes tipos: aquellas faltas con las que el individuo se enfrenta en la cotidianeidad de su existencia y que son resueltas por medio del castigo o del perdón, y aquellas ofensas que despiertan en la persona el sentimiento de que jamás deberían haber sucedido

\footnotetext{
${ }^{11}$ Canovan (1992) menciona que Arendt atribuye a la figura de Jesús de Nazaret ciertas concepciones políticamente relevantes que hacen a la naturaleza de la acción, a saber: la capacidad del ser humano para realizar milagros (en el sentido de llevar a cabo aquello que es por completo inesperado) y la posibilidad que tiene el individuo de comenzar una cadena nueva de acontecimientos por medio de la facultad del perdón que le permite revertir las consecuencias de los actos del pasado.
}

68 • Universidade Católica de Pernambuco 
y de que el agente de las mismas nunca debería haber nacido. Respecto del perdón como modo de responder a la transgresión, la autora sostiene que es exactamente lo contrario a la venganza, concebida por Arendt como una re-acción que no pone fin a la falta sufrida sino que, por el contrario, obliga a que el sujeto vengativo permanezca inmerso en el proceso desencadenado por la acción transgresora y no pueda interrumpir la cadena de consecuencias que toda acción implica. "[L]a venganza (...) es la reacción natural y automática a la transgresión (...) que (...) puede esperarse e incluso calcularse" (Arendt, 2009: 260) ${ }^{12}$. El perdón, en cambio, conserva la impredecibilidad inherente a la acción de la cual es un exponente. "[P]erdonar es la única reacción que no re-actúa simplemente, sino que actúa de nuevo y de forma inesperada" (Arendt, 2009: 260). El perdón rehabilita la acción y permite su continuidad, el individuo que perdona no perdona la falta cometida, el asesinato, el robo, sino que el perdón se dirige a la persona que transgredió la norma, que cometió la falta, y no a la obra fallida en sí (Vargas Bejarano, 2008).

Respecto a la noción de castigo, Arendt (2009) sostiene que es una alternativa al perdón pero no su opuesto. Según la autora, existe un impedimento natural a la hora de castigar aquello que no puede ser perdonado y viceversa. El mal totalitario es una ofensa que ejemplifica la mencionada imposibilidad de perdonar y castigar puesto que transciende, en la magnitud de su horror, tanto la esfera del ámbito humano como las potencialidades del hombre.

At the time the horror itself, in its naked monstrosity, seemed not only to me but to many others to transcend all moral categories and to explode all standards of jurisdiction; it was something men could neither punish adequately nor forgive (Arendt, 2003b, p. 23).

Arendt (2003c) hace hincapié en que el problema con los crímenes totalitarios radica precisamente en que sus perpetradores renunciaron voluntariamente a toda cualidad humana por lo que "no quedó nadie" que pueda ser susceptible de castigo o de perdón. Es en este sentido que Arendt afirma que el peor mal que existe es aquel realizado por seres humanos que renunciaron a su condición

\footnotetext{
${ }^{12}$ Respecto a la noción de venganza en el pensamiento arendtiano y su relación con el problema del mal, cf. Hilb (2015).
} 


\section{Ágora Filosófica}

de personas ${ }^{13}$. Si se tiene en cuenta que el perdón es una forma de la acción y que el mal acaecido durante el régimen totalitario surge como resultado de la anulación de la misma, la conclusión a la que se arriba es que ambas nociones, perdón y mal absoluto se encuentran en planos separados e incomunicables.

En cuanto al sujeto del perdón, Arendt (2009) menciona que es el mismo "quién" que se revela en el discurso y en la acción. La facultad de perdonar y de hacer promesas, en tanto preceptos morales, surge directamente de la voluntad del individuo, "[e]1 perdón perdona el qué en aras del quién restituyéndolo a su cualidad de agente libre" (Hilb, 2013b: 44). Arendt (2002) distingue con claridad la noción de perdón del concepto de reconciliación puesto que esta se encuentra íntimamente relacionada con el acto de comprender. "[C]omprender el totalitarismo no supone perdonar nada, sino reconciliarnos con un mundo en el que tales cosas son posibles" (Arendt, 2002: 18) ${ }^{14}$.

Vargas Bejarano (2008) señala que la reconciliación tiene su espacio en aquellos ámbitos donde ni el perdón ni el castigo pueden actuar. La reconciliación se dirige al mundo, no actúa de manera interpersonal, y su objetivo es el restablecimiento de la comunidad humana mediante la acción política. El perdón no es la condición ni la consecuencia de la comprensión, es una acción única que culmina en un único acto. La comprensión, por su parte, no se vincula con las personas sino que se relaciona con sus acciones y con los acontecimientos (Di Pego, 2007), el acto de comprender no tiene fin, sino que se renueva constantemente.

\section{El perdón puro según el análisis de Derrida}

En este apartado se realizará una breve exposición de las consideraciones sobre el perdón que Jacques Derrida brinda en la entrevista realizada por Michel Wieviorka en 1999 (Derrida,

\footnotetext{
${ }^{13}$ Arendt (2003c) hace una distinción entre la categoría de mero ser humano y la de persona, noción que surge del proceso mismo del pensamiento.

${ }^{14}$ Hilb (2013b) menciona que en los primeros trabajos arendtianos perdón y reconciliación eran considerados como opuestos pero que en la evolución de la teoría política arendtiana la reconciliación pasa a ser concebida como la condición de posibilidad del perdón entre iguales.

70 - Universidade Católica de Pernambuco
} 
$2003)^{15}$. El objetivo de esta exposición no es realizar un análisis minucioso de la propuesta derridiana, sino tomar algunas nociones clave, así como también las menciones que el autor realiza de la obra de Arendt, para luego ponerlas en cuestión con las reflexiones arendtianas. El foco principal de atención será el concepto de perdón puro en relación con la aporía del perdón, ambos conceptos inherentes a las consideraciones derridianas sobre el estatuto del perdón. La caracterización del perdón puro que realiza Derrida se asemeja en muchos aspectos a la definición arendtiana de la acción, fundamentalmente en lo que respecta al hecho de la natalidad, pero se distingue en su aplicabilidad a una determinada magnitud del mal que se mantiene imperdonable en el marco del análisis arendtiano.

El pensador observa que, desde la Segunda Guerra Mundial y hasta la actualidad, cada vez son más recurrentes en el ámbito global las escenas que hacen público tanto el arrepentimiento como el pedido de perdón por parte de diferentes instituciones públicas con el objetivo de resolver o dar un cierre a diferentes situaciones de violencia política.

La proliferación de estas escenas de arrepentimiento y de petición de "perdón"significa, sin duda, una urgencia universal de memoria (...) y este acto de memoria, de autoacusación, de arrepentimiento, de comparición, hay que llevarlo, a la vez, más allá de la instancia jurídica y de la instancia del Estado-nación (DERRIDA, 2003, p. 8) ${ }^{16}$.

Derrida (2003) analiza la noción de perdón como una categoría enmarcada en lo que él denomina la tradición abrahamánica, de modo que abarca las tres religiones más importantes de la humanidad: el islam, el cristianismo y el judaísmo. El supuesto del que parte Derrida es que existe lo imperdonable y la pregunta que ello le sugiere es si acaso el perdón

\footnotetext{
15 En este trabajo se utilizará la traducción al castellano de M. Segoviano publicada por Ediciones de la Flor.

${ }^{16}$ En este punto el autor menciona el surgimiento del concepto jurídico de crimen de lesa humanidad que fue propiciado por el mencionado proceso de comparición y acto de memoria de los estados-nación. Derrida (2003) considera que esta nueva categoría de crímenes se encuentra presente en el marco de toda geopolítica del perdón en el sentido de que le otorga legitimación.
} 
en sentido estricto únicamente se actualiza en la acción de perdonar lo imperdonable. El perdón, cuando está al servicio de una finalidad determinada, cuando está condicionado, deja de ser puro y desinteresado; el perdón no tiene como consecuencia la normalización ni es normativo en sí mismo sino que, por el contrario, debe ser y permanecer excepcional, "como si pudiera interrumpir el curso normal de la temporalidad histórica" (DERRIDA, 2003, p. 12). A los ojos del pensador, si el perdón alcanza solo aquello que parece perdonable, la idea misma del perdón se desvanece. En este punto se llega a lo que Derrida da en llamar la aporía del perdón, es decir, "el perdón perdona solo lo imperdonable" 17 (DERRIDA, 2003, p. 12).

Derrida (2003) pone énfasis en el error en el que caen algunos críticos al establecer una correlación inequívoca entre los conceptos de crimen de lesa humanidad, imprescriptibilidad y lo imperdonable. Que los crímenes contra la humanidad no prescriben es una realidad del derecho vigente, pero deducir de esto y de la magnitud del horror al que remiten la imposibilidad del perdón no se sustenta en evidencia alguna. En primer término porque la noción de perdón es y debe mantenerse ajena al ámbito jurídico y del derecho y, en segundo lugar, porque la experiencia demuestra que hay casos en los que el perdón es otorgado no obstante la inmensidad del mal perpetrado. Y, de manera inversa, casos en que no se perdonan transgresiones que podrían considerarse de menor gravedad. En otras palabras, el perdón no puede medirse, calcularse ni establecerse como consecuencia lógica de ningún razonamiento, o, como expresa Derrida, el perdón se mantiene fuera de la lógica condicional del intercambio.

En este sentido, es necesario distinguir y analizar la tensión existente entre el perdón puro, incondicional, infinito y gratuito que le es brindado al culpable en tanto culpable, respecto del perdón condicional que mide la falta y se otorga según su proporción, bajo la condición del arrepentimiento y la transformación del

\footnotetext{
${ }^{17}$ En la misma entrevista Derrida hace mención a otro sentido de la aporía, el cual tiene que ver con la falta de comprensión, de entendimiento, que puede existir entre la víctima y el transgresor. Tal falta de comunicación conduce a la imposibilidad del perdón. Si no hay un lenguaje común y un acuerdo sobre qué falta se cometió y quién fue el transgresor, no hay posibilidad alguna de perdón en tanto este pierde todo sentido.

72 - Universidade Católica de Pernambuco
} 
transgresor. Derrida (2003) sostiene que el perdón condicional ya no perdonaría al culpable sino a una versión diferente y mejorada del mismo. Esta concepción tradicional del perdón se construye sobre el supuesto de que el perdón tiene un sentido que se ve determinado ya sea por la promesa de la salvación futura, por la búsqueda de la reconciliación, de la expiación o de la redención. Con respecto al análisis realizado por Arendt respecto al concepto de perdón, y, a modo de ejemplo, Derrida menciona lo que a su criterio son las dos suposiciones de la pensadora, a saber: que la acción de perdonar es una posibilidad humana y que no se puede perdonar aquello que no puede ser castigado.

Derrida (2003) sostiene que el perdón es una suerte de locura de lo imposible, lo cual, en vez de descalificarlo lo describe en su incomprensible realidad. Así concebido, el perdón “es quizás la única cosa que ocurre, que sorprende, como una revolución, el curso ordinario de la historia, de la política y del derecho" (DERRIDA, 2003, p. 19).

Es en este sentido que el perdón se mantiene heterogéneo respecto al orden político puesto que en este nivel, y como se expuso, la acción de perdonar se concibe como una transacción o negociación que responde a la lógica del imperativo hipotético kantiano. Derrida está convencido de que el perdón no debe incluirse en el marco de la reconciliación principalmente porque en el caso de esta última, siempre entra en escena un tercero y la acción de perdonar debe llevarse a cabo, necesariamente, entre dos singularidades.

Derrida (2003) insiste en remarcar que existe una tensión entre la concepción incondicional y condicional del perdón, tensión que se mantiene desde los orígenes abrahamánicos de dicho concepto. El perdón incondicional debe ser dado gratuitamente, sin condición alguna, sin embargo, en su veta condicional, el perdón se otorga solo bajo la condición del arrepentimiento y la posterior transformación del transgresor. La conclusión a la que arriba el autor es que

si nuestra idea de perdón se derrumba desde el momento en que se la priva de su polo de referencia absoluto, a saber, de su pureza incondicional, no obstante continúa siendo inseparable de lo que le es heterogéneo, a saber, el orden de las condiciones, el 
arrepentimiento, la transformación, cosas todas que le permiten inscribirse en la historia, el derecho, la política, la existencia misma (DERRIDA, 2003, p. 24).

Los dos polos mencionados, el incondicional y el condicional, son irreductibles uno al otro pero, al mismo tiempo, indisociables. No hay manera de que el perdón se efectivice, de que transforme la realidad, si su pureza no se compromete con una serie de condiciones. Las decisiones y las responsabilidades deben tomarse en el "entre" que une-separa dichos polos.

El perdón puro, incondicional, dice Derrida (2003), para tener su sentido propio debe no tener sentido, finalidad alguna, debe permanecer ininteligible. Ahora bien, en el momento en que la víctima entra en comunicación con el transgresor, en cuanto lo comprende, el proceso de reconciliación ha comenzado y junto con él se ha dado inicio, también, a la acción usual de perdonar, la cual, a criterio del pensador, remite a muchas cosas menos al perdón.

Es menester distinguir entre el proceso de perdón y el de reconciliación, entendida esta como un punto final, como la "reconstitución de una salud o de una "normalidad" (DERRIDA, 2003, p. 29). Por el contrario, un perdón finalizado, culminado, no es un perdón sino, únicamente, una estrategia política o una necesidad terapéutica.

El perdón implica una incondicionalidad aneconómica, apolítica y no estratégica por lo que, en el universo geopolítico del perdón, en toda escena pública de arrepentimiento y pedido de perdón, Derrida encuentra una falta de respeto hacia la víctima y hacia el concepto mismo de perdón y la tradición implicada en él. Esto último, sostiene el autor, no alude exclusivamente a un purismo semántico-filosófico, sino que, en pos del rigor conceptual que tal afirmación reclama se quiere remarcar que toda maniobra o estrategia política puede ampararse de manera abusiva en el marco del pedido de perdón para eludir las instancias del derecho. El perdón acarrea un cierto no-saber, un secreto que permanece siempre sin develar y al que el plano jurídico-legal no puede acceder, incluso debe permanecer intacto ante la moral en su condición de absoluto. "En el mal radical (...) y en consecuencia en el enigma del perdón de lo imperdonable, hay una especie de 
'locura' que lo jurídico-político no puede abordar, menos aún apropiarse” (DERRIDA, 2003, p. 34).

\section{El concepto de perdón en Arendt y Derrida. ¿Dos concepciones opuestas sobre lo imperdonable?}

Si se tiene en cuenta lo expuesto en los parágrafos anteriores, de manera apresurada se podría aventurar que la concepción arendtiana del perdón se complementaría con la propuesta y el análisis de Derrida (2003), en tanto Arendt concibe el perdón como una posibilidad humana que encuentra su límite de acción en el mal absoluto y Derrida, por el contrario, considera que el perdón en sentido puro tiene su razón de ser precisamente cuando actúa en aquellos casos que se creen imperdonables. En otras palabras, el alcance del concepto arendtiano de perdón termina donde comienza el ámbito de acción del perdón puro derridiano.

Ahora bien, a los efectos de que tal complementariedad sea corroborada es imprescindible, en este apartado, ahondar en las cuestiones nodales que hacen al hilo argumental de las teorías de ambos autores respecto al perdón, así como también analizar las divergencias y los posibles puntos de encuentro de ambas propuestas teóricas. Una vez hecho esto, se intentará dar argumentos en pos de la hipótesis de la complementariedad en tanto se cree que, si se toma en consideración la concepción arendtiana del perdón y de la acción (específicamente el hecho de la natalidad), y se la fusiona con la propuesta de Derrida, el perdón podría ser visto como la máxima y más completa expresión de la acción humana, así como también se vería ampliado su arco de alcance (si se lo analiza desde la óptica arendtiana). Al mismo tiempo, se considera indispensable evaluar si dicha fusión implicaría necesariamente una distorsión de la teoría de la acción propuesta por Arendt.

En el marco de la teoría arendtiana el perdón, en tanto facultad de carácter político, posee el mismo estatus que la acción (por ser un modo de ella) y comparte con esta la pluralidad como condición de posibilidad. Madrid Gómez Tagle (2008) sostiene que si el espacio público arendtiano no se caracterizara por la pluralidad, y la acción no fuera irreversible ni sus consecuencias 
imprevisibles, el perdón no tendría razón de ser. Arendt (2009) sostiene que una de las diferencias entre el perdón y la venganza es, justamente, que el primero es imprevisible y la última, en cambio, es siempre una reacción esperable. El perdón también se identifica con la acción mediante la natalidad, pues al surgir de la espontaneidad humana, al igual que la capacidad de actuar, el perdón actúa de manera inesperada e imprevisible y tiene la posibilidad de insertar algo nuevo en el mundo (Madrid Gómez Tagle, 2008). De las definiciones arendtianas de los mencionados conceptos se deduce que el perdón se da, necesariamente, de la mano de la noción de natalidad, no así a la inversa.

En la caracterización de la categoría de natalidad que fue expuesta con anterioridad se hizo hincapié en su condición de evento espontáneo, inesperado. La raíz natal de la acción humana es concebida por Arendt como una suerte de milagro que salva al mundo de su ruina. El perdón, por su parte, deviene a lo largo de la evolución del pensamiento de la autora, en una facultad política que tiene la virtud de revertir las consecuencias de los actos del pasado así como también la capacidad de reactivar la acción. En otras palabras, la acción, por medio de la natalidad, irrumpe e interrumpe el curso de los acontecimientos de manera espontánea e inesperada. El perdón, por su parte, también se inserta en el mundo de forma imprevista pero, a diferencia de la natalidad, en el mismo acto de perdonar se revierten las consecuencias de las acciones pasadas y se reactiva la acción. De esto podría desprenderse que el perdón, como un modo de la acción, encarna en su máximo sentido la capacidad milagrosa del actuar mismo que Arendt le atribuyera a la condición natal de la acción en tanto la capacidad de desandar la línea temporal y de revertir las consecuencias de la acción podrían considerarse virtudes sobrehumanas y, en este sentido, milagrosas.

Ahora bien, Arendt sostiene que el perdón se ve limitado ante el mal absoluto debido a que únicamente tiene injerencia en el marco de la acción humana, mientras que el mal totalitario, precisamente, tiene como una de sus notas distintivas la anulación de la posibilidad de la acción. Sin embargo, si se tiene en cuenta el análisis de Derrida (2003) en el que se promulga una noción incondicionada de perdón y ajena a cualquier tipo de lógica y razonamiento, el mal absoluto podría y debería ser perdonado.

Derrida (2003) no separa los ámbitos del perdón y de lo 
imperdonable sino que, por el contrario, en lo que el pensador da en llamar la aporía del perdón (perdonar lo imperdonable) radica la razón de ser del perdón puro. "Fuera de la lógica de la expiación, de las condiciones y de la proporción, el perdón se instala en el pensamiento derridiano como una "locura de lo imposible" (ROJAS ÁVILA, 2013, p. 180).

Derrida (2003) se refiere al perdón puro como un gesto de locura en tanto no responde a ningún tipo de lógica ni es la conclusión de ningún razonamiento. Es inexplicable y, de alguna manera, puede ser inentendible. La pureza del perdón radica en que se da sin condición alguna, no responde a ningún tipo de intercambio puesto que no requiere del arrepentimiento ni de la transformación del transgresor. La inaccesibilidad racional del perdón, esta suerte de "secreto", es una condición que, a criterio de Derrida, debe permanecer intacta, absoluta. Arendt (2009), por su parte, le atribuye a la condición natal de la acción humana un halo milagroso por su capacidad de irrumpir en el mundo de manera inesperada e imprevisible y de cambiar el curso de la cadena causal de los acontecimientos.

Los conceptos de locura y milagro no son equivalentes, sin embargo podría decirse que comparten ciertas características o se encuentran relacionados en determinados aspectos. De hecho, la tradición occidental cuenta con diversos casos en los que los hacedores de milagros han sido tildados de locos por aquellos ajenos a sus creencias ${ }^{18} \mathrm{y}$, al igual que la locura, el milagro no puede ser entendido ni explicado racionalmente. Ambos conceptos comparten la condición de ser espontáneos, inesperados, imprevisibles, ilógicos e inexplicables. Y si bien se podría objetar que el "milagro de la acción" al que hace referencia la teoría arendtiana responde a una decisión deliberada y meditada por parte del individuo, cuestión que lo pondría en oposición con la concepción tradicional de la locura, la semejanza que aquí se establece entre milagro y locura no pretende ser exhaustiva sino que responde a la intención de marcar algunos puntos de encuentro que permitan establecer una relación entre ambos conceptos.

Ahora bien, si se tiene presente, por un lado, que la acción

18 Al respecto, cabe mencionar el caso de "los santos locos" en la Antigüedad Tardía y Bizancio. Para una profundización del tema, cf. Fuertes (2012). 
en sentido arendtiano tiene la capacidad de revolucionar el mundo por medio de la interrupción de la cadena causal de los acontecimientos, y que tal facultad se fundamenta en las nociones de natalidad y perdón y, por otro lado, que el perdón puro derridiano se caracteriza por irrumpir de manera revolucionaria en el mundo, en el sentido de que "[e]sa es quizás la única cosa que ocurre, que sorprende, como una revolución, el curso ordinario de la historia, de la política y del derecho" (DERRIDA, 2003, p. 19), puede afirmarse que, en el marco del pensamiento arendtiano, la acción alcanzaría su punto máximo al perdonar el mal totalitario.

No obstante, la teoría arendtiana de la acción se ve limitada en lo que respecta al mal absoluto en tanto le es imposible acceder a su ámbito de existencia y, en consecuencia, carece de la capacidad de transformarlo, de ponerle un fin. En el mundo en el que piensa Arendt el mal absoluto no debería haber ocurrido y sus perpetradores no deberían haber nacido. Pero, a su vez, ese mal ocurrió y sus perpetradores nacieron y se formaron hasta ser capaces de idearlo y llevarlo a cabo. ¿Qué puede hacerse, entonces, en el marco de la teoría arendtiana, al respecto?

Como se vio, según las propias palabras de la autora no hay lugar para el castigo ni la venganza, la reconciliación, por su parte, se vincula estrechamente con la comprensión y ambas aplican al mundo en el que el mal totalitario tuvo lugar, no así a los perpetradores de dicho mal ni al mal en sí mismo. En lo que respecta al perdón, el análisis arendtiano se limita a sostener que no aplica al mal acaecido durante el régimen nazi por ser un modo de la acción, la cual fue anulada durante el mencionado gobierno totalitario.

A modo de ejemplo, si se analiza la reacción arendtiana a la sentencia del juicio a Eichmann en Jerusalén, se puede ver cómo la pensadora adhiere, aunque con argumentos diferentes a los expuestos por el tribunal, a la condena a muerte del procesado. Queda en evidencia, así, que la única opción que Arendt encuentra en lo que a los agentes del mal absoluto respecta es la muerte, específicamente, el ahorcamiento ${ }^{19}$.

Y del mismo modo que tú apoyaste y cumplimentaste

${ }^{19}$ Respecto al controvertido discurso que ofrece Arendt en el Post Scriptum de Eichmann en Jerusalén y su acuerdo con la condena a muerte de Eichmann en la horca, cf. Butler (2011) y Young-ah Gottlieb (2011).

78 • Universidade Católica dePernambuco 
una política de unos hombres que no deseaban compartir la tierra con el pueblo judío ni con ciertos otros pueblos de diversa nación - como si tú y tus superiores tuvierais el derecho de decidir quién puede y quién no puede habitar el mundo-, nosotros consideramos que nadie, es decir, ningún miembro de la raza humana, puede desear compartir la tierra contigo. Esta es la razón, la única razón, por la que has de ser ahorcado (ARENDT, 2003a, p. 166).

El análisis derridiano, por su parte, sostiene que el perdón en sentido puro solo cobra relevancia cuando es dado a aquel que realizó el peor de los males y no se encuentra arrepentido. $\mathrm{Su}$ capacidad revolucionaria, su locura, acaece en el momento en que se perdona aquello que nadie espera ni entiende que sea perdonado.

El perdón, en este caso, parece ser una vivencia personal, interna, de la víctima que tiene lugar al margen de la actitud que adopte el transgresor. No parece haber interacción ni intercambio alguno entre ambos. En el caso arendtiano, por el contrario, el perdón se da en interrelación estrecha entre la víctima y el transgresor, al punto de que la actitud de este último en el momento de cometer el acto es una de las cuestiones a tener en cuenta por la víctima a la hora de perdonar.

En el marco de la teoría arendtiana de la acción, el mal totalitario no puede ser perdonado porque tiene lugar fuera del ámbito de alcance del actuar humano, anula el "entre" que se da en la pluralidad del espacio público así como también la espontaneidad e imprevisibilidad inherentes a la acción misma. Sin embargo, si se tiene en cuenta que las consecuencias del mencionado mal repercuten directamente en el ámbito de la acción en tanto la anulan o imposibilitan, sería legítimo esperar que Arendt ofreciera alguna alternativa desde el actuar mismo que no fuera, únicamente, la muerte del transgresor, o, en todo caso, que ofreciera alguna reflexión sobre las posibles contradicciones que la aceptación de la pena de muerte generaría al interior de sus consideraciones anteriores en tanto puede interpretarse como una apelación a la venganza y a una concepción retributiva de la justicia $^{20}$.

${ }^{20}$ Ver nota $\mathrm{n}^{\mathrm{o}} 12$ 
En la propuesta de Derrida (2003) se encuentra, quizá, una posible línea de acción que se adecua al análisis arendtiano del perdón y el mal absoluto. Lejos de tergiversar o forzar la teoría de Arendt, en el aporte derridiano se puede ver cómo el perdón puro, aquel perdón que se da sin esperar nada a cambio y que responde al peor de los males, presenta las características que la pensadora le atribuye a la acción en general (específicamente en relación con el hecho de la natalidad) y al perdón en particular. El perdón puro que describe Derrida (2003) puede ser concebido como la máxima expresión de las potencialidades de la acción humana en sentido arendtiano $^{21}$. En el acto de perdonar al ejecutor del mal absoluto adviene el milagro, es decir, aquello completamente inesperado e inentendible, un gesto de locura que, en su hacerse realidad, no solo establece un nuevo comienzo sino que, al mismo tiempo, abre un mundo infinito de posibilidades.

\section{Conclusión}

En el marco de la obra arendtiana el concepto de perdón adquiere un status de relevancia al ser la única modalidad de la acción que tiene la facultad de revertir las consecuencias de los actos del pasado y de dar inicio de forma inesperada y espontánea a una nueva cadena de acontecimientos, capacidad que comparte con la noción de natalidad. Por ser un tipo de acción, el perdón no tiene la capacidad de ejercer su poder en lo que respecta al mal totalitario, una especie de mal que excede, en la magnitud de su horror, el ámbito humano de la acción.

En esta investigación, luego de realizarse una aproximación a las nociones arendtianas de acción y natalidad, se analizó, por un lado, el concepto de perdón en la concepción teórica de la autora y su relación con las categorías de castigo, venganza, reconciliación, comprensión y, por otro, se puso el acento en la imposibilidad humana de perdonar el mal absoluto. En un segundo momento se expuso el análisis del perdón condicional e incondicional (perdón

\footnotetext{
${ }^{21} \mathrm{Al}$ respecto, cabe aclarar que no se podría hablar de "pureza" del perdón dentro del marco de análisis arendtiano porque algo así como una esencia verdadera o pura de un tipo de acción, en este caso, del perdón, es incompatible con un pensamiento que se aboca al análisis de la contingencia y los acontecimientos en su facticidad.
}

80 • Universidade Católica de Pernambuco 
puro) que brinda Derrida en la entrevista que le realizara Wieviorka en 1999. El objetivo de la mencionada incursión en el pensamiento derridiano fue poner en cuestión la concepción arendtiana del perdón con el aporte del pensador, quien de manera explícita menciona el análisis de Arendt y, específicamente respecto a la imposibilidad de perdonar el mal absoluto, disiente con la pensadora. Por último, se toman los puntos clave de las concepciones del perdón de ambos pensadores a los efectos de contrastarlas y analizar la posibilidad de que los aportes de una de las propuestas (la derridiana) complementen y brinden una solución a los límites y las falencias de la otra (la arendtiana).

A modo de conclusión, en este trabajo se pudo observar que la caracterización del perdón puro que ofrece Derrida (2003) presenta características que se asemejan a la concepción arendtiana de la acción de perdonar pero en sentido superlativo. Es decir, la facultad de revolucionar y cambiar el curso de los acontecimientos que tiene el concepto de perdón en la obra de Arendt se ve maximizada en el acto de perdonar el mal absoluto en el sentido de que no existe nada más inesperado e inexplicable, nada más milagroso, que perdonar el mal totalitario.

\section{Referências}

ARENDT, H. "Understanding and Politics", Partisan Review, Vol. 20, No 4, (1953) p. 377-392.

"Labor, trabajo y acción. Una conferencia". En: ARENDT, Hannah, De la historia a la acción, Barcelona, Paidós, (1995) p. 89-107. ¿Qué es política? Barcelona, Paidós, 1997.

Los orígenes del totalitarismo. Buenos Aires, Taurus, 1998. El concepto de amor en san Agustín. Madrid, Encuentro, 2001.

"Comprensión y política. Las dificultades de la comprensión",

$\overline{\Delta \alpha i \mu \omega v}$. Revista de filosofía, $\mathrm{N}^{\circ} 26,(2002)$ p. 17-30.

Eichmann en Jerusalén. Un estudio sobre la banalidad del mal.

Barcelona, Lumen, 2003a.

"Personal Responsibility Under Dictatorship". En: ARENDT,

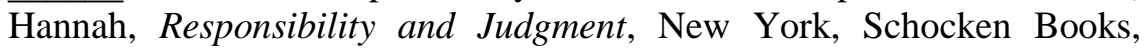
(2003b) p. 17-48.

"Some Questions of Moral Philosophy". En: ARENDT, Hannah, Responsibility and Judgment, New York, (2003c) p. 49-146.

"The Eichmann Controversy. A letter to Gershom Scholem". En: 
ARENDT, Hannah, The Jewish Writings, New York, Schocken Books Press, (2007) p. 465-471.

La condición humana. Buenos Aires, Paidós, 2009.

BABICH, B. "Arendt's Radical Good and the Banality of Evil. Echoes of Scholem and Jaspers in Margarethe von Trotta's Hannah Arendt", An International Journal in Philosophy, Religion, Politics and the Arts, Vol. 9, $\mathrm{N}^{\circ} 2$, (2014) p. 13-26.

BAGEDELLI, P. "Entre el ser y la vida: el concepto de natalidad en Hannah Arendt y la posibilidad de una ontología política", SAAP, Vol. 5, $\mathrm{N}^{\mathrm{o}}$ 1, (2011) p. 37-58.

BÁRCENA, F. "Hannah Arendt: Una poética de la natalidad", $\Delta \alpha i \mu \omega v$ Revista de Filosofía, № 26, (2002) p. 107-123.

BERNSTEIN, R. “¿Cambió Hannah Arendt de opinión? Del mal radical a la banalidad del mal". En: BIRULÉS, Fina (Comp.), Hannah Arendt. El orgullo de pensar, Barcelona, Editorial Gedisa, (2000) p. 235-257.

BILSKY, L. "The Arendt Controversy 2000: An Israeli Perspective", Journal for Political Thinking, Vol. 5, No 1, (2001) p. 44-46.

BIRULÉS, F. “¿Por qué debe haber alguien y no nadie?”. En: ARENDT, Hannah, ¿Qué es política?, Barcelona, Paidós, (1997) p. 9-40.

"Hannah Arendt: modernidad, identidad y acción", $\Delta \alpha i ́ \mu \omega v$ Revista de Filosofía, № 26, (2002) p. 21-29.

BUTLER, J. "Hannah Arendt's Death Sentences", Comparative Literature Studies, Vol. 48, No 3, (2011) p. 280-295.

CANOVAN, M. Hannah Arendt. A Reinterpretation of Her Political Thought. Cambridge, Cambridge University Press, 1992.

"Introduction". En: ARENDT, Hannah, The Human Condition, Chicago, The University of Chicago Press, (1998) p. vii-xx.

"Hannah Arendt como pensadora conservadora". En: BIRULÉS,

Fina (Comp.), Hannah Arendt. El orgullo de pensar, Barcelona, Gedisa, (2000) p. 51-75.

DERRIDA, J. El siglo y el perdón. Fe y saber. Buenos Aires, Ediciones de la flor, 2003.

DI PEGO, A. "Las concepciones del mal en la obra de Hannah Arendt. Crítica de la modernidad y retorno a la filosofía", Al Margen, $\mathrm{N}^{\circ} 21-22$, (2007) p. 1-15.

FUERTES, F. "Simeón 'el loco': los rasgos demoníacos de un monje aparentemente extraño", Collectanea Christiana Orientalia, No 9, (2012) p. 81-103.

HAYDEN, P. "The Relevance of Hannah Arendt's Reflections on Evil: Globalization and Rightlessness", Human Rights Review, No 11, (2010) p. 451-467.

HILB, C. “¿Cómo fundar una comunidad después del crimen? Una reflexión sobre el carácter político del perdón y la reconciliación, a la luz

82 - Universidade Católica de Pernambuco 
de los Juicios a las Juntas en la Argentina y de la Comisión de la Verdad y la Reconciliación en Sudáfrica", Discusiones, No 12, (2013a) p. 31-58.

"Justicia, reconciliación, perdón", African Yearbook of Rhetoric, Vol. 3, No 2, (2013b) p. 41-52.

"Por eso, Sr. Eichmann, debe Ud. colgar. De Eichmann en Jerusalén a los "Juicios" en Argentina (Reflexiones situadas)", African Yearbook of Rhetoric, Vol. 6, No 1, (2015) p. 1-13.

JONAS, H. "Actuar, conocer, pensar. La obra filosófica de Hannah Arendt”. En: BIRULÉS, Fina (Comp.), Hannah Arendt. El orgullo de pensar. Barcelona, Gedisa, (2000) p. 23-40.

KRISTEVA, J. Hannah Arendt. Life is a Narrative. Toronto, University of Toronto Press, 2001.

LÓPEZ, M. "La reversibilidad del tiempo, el perdón y la promesa en Hannah Arendt", Investigaciones Fenomenológicas, Vol. monográfico 3, (2011) p. 265-278.

MADRID GÓMEZ TAGLE, M. "Sobre el concepto de perdón en el pensamiento de Hannah Arendt", Praxis Filosófica, No 26, (2008) p. 131149.

NEIMAN, S. "Banality Reconsidered". En: BENHABIB, Seyla (Ed.), Politics in Dark Times. Encounters with Hannah Arendt, New York, Cambridge University Press, (2010) p. 305-315.

PENDAS, D. "Eichmann in Jerusalem', Arendt in Frankfurt: The Eichmann Trial, the Auschwitz Trial, and the Banality of Justice", New German Critique, № 100, (2007) p. 77-109.

RAMÍREZ, H. "Humanidad, libertad y perdón en Hannah Arendt: realidades básicas para la razón práctica en el marco de la diversidad cultural", Persona y derecho, $\mathrm{N}^{\circ}$ 61, (2009) p. 249-281.

ROJAS ÁVILA, R. "En la medida de lo (im)posible: las aporías del perdón, la memoria y el duelo a 40 años del golpe de estado en Chile", Universum. Revista de Humanidades y Ciencias Sociales, Vol. 2, $\mathrm{N}^{\circ} 28$, (2013) p. 169-187.

TSAO, R. "Arendt's Augustine". En: BENHABIB, Seyla (Ed.), Politics in Dark Times. Encounters with Hannah Arendt, New York, Cambridge University Press, (2010) p. 39-57.

VARGAS BEJARANO, J. "Reconciliación como perdón. Una aproximación a partir de Hannah Arendt", Praxis Filosófica, № 26, (2008) p. 111-129.

VATTER, M. "Natality and Biopolitics in Hannah Arendt", Revista de Ciencia Política, Vol. 26, № 2, (2006) p. 137-159.

YOUNG-AH GOTTLIEB, S. "Beyond Tragedy: Arendt, Rogat, and the Judges in Jerusalem", College Literature, Vol. 38, No 1, (2011) p. 45-56. 